\title{
Conductive glass sealants with Ag nanoparticles prepared by heat reduction process
}

\author{
Takafumi Akamatsu ${ }^{1,2}, *$ Woosuck Shin ${ }^{1,2}$, Toshiaki Yamaguchi ${ }^{1,2}$, \\ Yoshinobu Fujishiro ${ }^{1,2}$, Toshio $\operatorname{Itoh}^{1}$, and Noriya Izu ${ }^{1}$ \\ ${ }^{1}$ National Institute of Advanced Industrial Science and Technology (AIST), \\ Advanced Manufacturing Research Institute, \\ 2266-98, Anagahora, Shimo-Shidami, Moriyama-ku, \\ Nagoya, 463-8560, Japan \\ ${ }^{2}$ CREST, Japan Science and Technology Agency (JST), \\ 2266-98, Anagahora, Shimo-Shidami, Moriyama-ku,
} Nagoya, 463-8560, Japan

*To whom correspondence should be addressed: (T. Akamatsu) t-akamatsu@aist.go.jp (Fax: +81-52-736-7244) 
Keywords: glass sealant; silver; silver chloride; heat reduction 


\section{Introduction}

Organic conductive sealants, which consist of organic polymeric resins and conductive fillers, have been investigated due to the application to microelectrical packaging such as in surface mounting technology and liquid crystal display [1]. Furthermore, a numerous research work has also been performed in the effort to replace traditional lead-based solders with polymer/filler composites in order to reduce the amount of toxic substances [2]. Since the polymer/filler composites are composed of organic polymer with a thermal decomposition temperature about $300^{\circ} \mathrm{C}$, the polymer/filler composites have generally used at room temperature to $200^{\circ} \mathrm{C}$.

An inorganic oxide glass, which typically has the coefficient of thermal expansion of $6 \times 10^{-6}$ to $10 \times 10^{-6} \mathrm{~K}^{-1}$, has been used as a sealing component between ceramic and metal materials [3]. Among the inorganic oxide glasses, silicate and borosilicate glasses, which does not contain rare earth elements and toxic components, have been used as low cost glass sealants for high temperature. Recently, the glass sealants are applied to electrochemical devices such as solid oxide fuel cells [4-6] and zirconia oxygen sensors [7] under high temperature. The glass sealants need to have high gas sealability, mechanical/chemical durability, and also high electrical property of insulation. Therefore, composites consisting of insulative matrix of glass and conductive filler of metal (e.g., silver, gold, or palladium) are used as promising candidates for high temperature conductive sealants for solid oxide fuel cells. Moreover, the conductive inorganic composite material is used as an interconnect connecting between the fuel cell single units instead of a gastight conductive paste [5]. Although the mixture of the glass powder and metal filler is conventionally obtained by utilizing a mechanical mixer and shaker, a homogeneous mixture is hardly prepared due to the aggregation of same 
particles [6]. To obtain the conductive glass/filler composite sealants prepared by a conventional mixing method, high filler content is required, resulting in manufacturing and any possible problem of gas sealability, also to be considered.

In this work, a low metal content but highly noble conductive borosilicate glass sealant has been developed, whose synthesis conditions are much different from a conventional mixing method. The glass sealant was prepared by a heat reduction process of glass/ $\mathrm{AgCl}$ composite powder and their microstructures and electrical properties were investigated.

\section{Experimental procedure}

A glass with a nominal composition of $5 \mathrm{SiO}_{2}-40 \mathrm{~B}_{2} \mathrm{O}_{3}-5 \mathrm{MgO}-10 \mathrm{CaO}-30 \mathrm{ZnO}-5 \mathrm{Na}_{2} \mathrm{O}-5 \mathrm{~K}_{2} \mathrm{O}(\mathrm{mol} \%)$ was prepared by melting a batch mixture of commercially available reagent-grade chemicals such as $\mathrm{SiO}_{2}, \mathrm{H}_{3} \mathrm{BO}_{3}$, $\mathrm{Mg}(\mathrm{OH})_{2}, \mathrm{CaCO}_{3}, \mathrm{ZnO}, \mathrm{Na}_{2} \mathrm{CO}_{3}$ and $\mathrm{K}_{2} \mathrm{CO}_{3}$ in a $\mathrm{Pt}$ crucible at $1100^{\circ} \mathrm{C}$ in air atmosphere for $0.5 \mathrm{~h}$. The melt was poured onto an iron plate and quenched by iron pressing, to obtain glass flakes. The glass flakes were milled into glass powder using an alumina mortar and pestle. The powder was passed through a $106 \mu \mathrm{m}$ sieve to remove the coarse particles. The fine glass powder after sieving was denoted as a normal glass (N-glass) powder.

The preparation of an Ag-precipitated glass (AP-glass) powder is as follows (see Fig. 1.). The N-glass was mixed with commercially $\mathrm{AgCl}$ powder. The weight ratios of mixtures of the $\mathrm{N}$-glass and $\mathrm{AgCl}$ powder were from 75:25 to 40:60. After the mixtures were molten in alumina crucible at $900^{\circ} \mathrm{C}$ in air atmosphere for $0.5 \mathrm{~h}$, the melt was poured onto an iron plate and quenched by iron pressing, to obtain glass/ $\mathrm{AgCl}$ 
composite flakes. The glass/ $\mathrm{AgCl}$ composite flakes were milled into glass/ $\mathrm{AgCl}$ composite powder using an alumina mortar and pestle. The glass/ $\mathrm{AgCl}$ composite powder was passed through a $106 \mu \mathrm{m}$ sieve to remove the coarse particles. The glass/ $\mathrm{AgCl}$ composite powder after sieving was treated with a heat reduction at $400^{\circ} \mathrm{C}$ for $40 \mathrm{~h}$ under $5 \% \mathrm{H}_{2} / 95 \% \mathrm{~N}_{2}$ atmosphere in order to reduce $\mathrm{AgCl}$ into $\mathrm{Ag}$.

The preparation procedure of a mechanical Ag-mixed glass powder (MA-glass) is as follows (see Fig. 1.). A mixture of the N-glass and a commercially available silver powder (Dowa Electronics Materials Co., Ltd.) having an average particle diameter of 300 or $20 \mathrm{~nm}$ was prepared using a hybrid mixer (Keyence HM-500). The weight ratios of the mixtures of the $\mathrm{N}$-glass and the silver powder were $80: 20,75: 25,70: 30,65: 35$, 60:40 and 50:50, as called MA-glass(20\%), MA-glass(25\%), MA-glass(30\%), MA-glass(35\%), MA-glass(40\%) and MA-glass(50\%), respectively. The MA-glass consisting of 300 and $20 \mathrm{~nm}$ Ag powder was denoted as M300A-glass and M20A-glass, respectively. Fig. 1 shows a schematic drawing of the preparation of the N-glass, AP-glass, M300A-glass and M20A-glass.

The obtained sample powder was characterized by differential thermal analysis (DTA), X-ray diffraction (XRD) analysis and scanning electron microscopy (SEM). DTA was carried out using a TG-DTA2010SA (Bruker AXS K.K.). XRD analysis was carried out using a RINT 2100V/PC instrument (Rigaku Corporation) equipped with a copper source $(\mathrm{CuK \alpha})$. SEM was carried out using a JSM-6335FM microscope (JEOL Ltd.) equipped with a field-emission gun.

To make glass pastes, the glass powder was mixed with an organic vehicle consisting of ethyl cellulose and terpineol using a Keyence HM-500 hybrid mixer. The content of the ethyl cellulose in terpineol in this study was $4 \mathrm{wt} \%$. The weight ratio of 
the mixture of the obtained sample powder and organic vehicle was 80:20. The glass paste was subsequently deposited on an alumina substrate with platinum comb-type electrodes, which have a $200 \mu \mathrm{m}$ electrode gap and $100 \mu \mathrm{m}$ electrode width within 3.4 $\mathrm{mm} \times 4 \mathrm{~mm}$ area, using an air-dispenser (Musashi engineering FAD320s). The glass paste-deposited substrate was baked at $800^{\circ} \mathrm{C}$ for $2 \mathrm{~h}$ in air atmosphere, then a glass thick film with was formed on the substrate.

Electrical resistance of the sample was measured by 2 probes method using a digital multimeter (Keithley Model 2700) at temperature between 400 and $700^{\circ} \mathrm{C}$. The electrical resistance was measured at 1-minute intervals for $0.5 \mathrm{~h}$ and the average electrical resistance $(R)$ and standard deviation were estimated. The sample films after the measurements were broken and the cross sections of the broken films were observed using SEM.

\section{Results and discussion}

Fig. 2 shows DTA curve of the N-glass. The glass transition temperature was found to be $484^{\circ} \mathrm{C}$ indicated from first inflection point, and no exothermic peaks due to the crystallization were observed. In our preliminary experiments, when the N-glass was treated with the heat reduction at $400^{\circ} \mathrm{C}$ for $40 \mathrm{~h}$ under $5 \% \mathrm{H}_{2} / 95 \% \mathrm{~N}_{2}$ atmosphere, no remarkable structural changes such as a crystallization and adhesion between the glass particles were confirmed owing to the heat reduction below the glass transition temperature. The melt of the $\mathrm{N}$-glass with network modifiers such as alkali and alkaline earth components showed suitable viscosity and was possible to mix with $\mathrm{AgCl}$ melt at $900^{\circ} \mathrm{C}$

Fig. 3 shows the photographs of the glass/AgCl composite powder with the 
weight ratio of 60:40 as prepared in air atmosphere and after the heat reduction at $400^{\circ} \mathrm{C}$ for $40 \mathrm{~h}$ in $5 \% \mathrm{H}_{2} / 95 \% \mathrm{~N}_{2}$ atmosphere. After the heat reduction, the white powder converted into the grey powder. Fig. 4 shows XRD patterns of the glass/AgCl composite powder with the weight ratio of 60:40 as prepared in air atmosphere and after the heat reduction at $400^{\circ} \mathrm{C}$ for $40 \mathrm{~h}$ in $5 \% \mathrm{H}_{2} / 95 \% \mathrm{~N}_{2}$ atmosphere. The XRD patterns had some peaks due to crystalline phases and broad halo pattern due to amorphous phase. Before the heat reduction, the peaks due to $\mathrm{AgCl}$ were confirmed. After the heat reduction, no peak due to $\mathrm{AgCl}$ was found and the peaks due to $\mathrm{Ag}$ were identified confirming the reduction of $\mathrm{AgCl}$ into $\mathrm{Ag}$. The conversion of $\mathrm{AgCl}$ into $\mathrm{Ag}$ completely proceeded because no peaks due to $\mathrm{AgCl}$ were remained in the XRD pattern of the composite powder after the heat reduction. The heat reduction reaction was considered to be the following equation: $\mathrm{AgCl}+1 / 2 \mathrm{H}_{2} \rightarrow \mathrm{Ag}+\mathrm{HCl}$. The Ag contents of the AP-glass after heat reduction process and MA-glass are calculated as in Table 1. The composite powder with the weight ratios of the $\mathrm{N}$-glass and $\mathrm{AgCl}$ powder of 60:40 after heat reduction were denoted as AP-glass(33\%). We investigated the composition with the 5wt\% change of $\mathrm{Ag}$ content, so that the error can be induced in this study would be around $5 \mathrm{wt} \%$ composition. Borrelli et al reported photochromic glasses derived from treating alkali aluminoborosilicate glasses with silver halide in a reducing atmosphere [8]. However, the photochromic glasses contained about $0.53 \mathrm{wt} \% \mathrm{Ag}$ in the glass and are considered to be no electrical conductivity because of low Ag content. In our preparation method, the mixture of the glass and $\mathrm{AgCl}$ was molten at $900^{\circ} \mathrm{C}$. Since the melting at $900^{\circ} \mathrm{C}$ was successful to control both the volatilization of chlorine and the generation of Ag melt, the composite with a high $\mathrm{AgCl}$ content was obtained, resulting in the formation of the glass powder with a high Ag content after heat reduction process. 
Fig. 5 shows SEM images of the AP-glass(33\%) particles. In Fig. 5a, the fractured particles of the size of about $100 \mu \mathrm{m}$ were observed. An SEM image of the high magnification of the fractured surface of glass particle in Fig. 5a was shown in Fig. 5b. In Fig. 5b, bright spherical particles with diameter of 100 to $300 \mathrm{~nm}$ in the dark glass matrix were observed. To assign the spherical particle, the fractured particle surface was observed in backscattered electron (BSE) mode as shown in Fig. 5c. The BSE detection allows the identification of high atomic number elements because they appear brighter on the image [9]. So that, Ag would be brighter than the lighter elements in the glass matrix such as $\mathrm{Si}, \mathrm{Ca}, \mathrm{Mg}$ and $\mathrm{Zn}$ in BSE mode; the spherical particles were assigned to Ag particles. In addition to the particles with diameter sizes of 100 to 300 $\mathrm{nm}$, small spherical particles with diameter of 20 to $30 \mathrm{~nm}$ were observed as shown in Fig. 5d, higher magnification. These small spherical particles were supposed to be Ag particles since they were slightly brighter than the matrix, and may be embedded in the matrix. The AP-glass(33\%) had the dispersed Ag particles of diameter of 20 to $300 \mathrm{~nm}$.

Fig. 6a shows SEM image of the M300A-glass(35\%). In Fig. 6a, the fractured particles of the size of about $100 \mu \mathrm{m}$ were observed and a different kind of large particle over $100 \mu \mathrm{m}$ was also observed in the upper right corner of Fig. 6a. Fig. 6b shows SEM image of the high magnification of the fractured particle surface. In Fig. 6b, An agglomerated Ag particle of the size of about $800 \mathrm{~nm}$ was shown but it was sparse on the fractured surface of glass. Fig. 6c shows SEM image of the high magnification of the large particle in the upper right corner of Fig. 6a. As shown in Fig. 6c, it was considered that this particle is composed of Ag particles with a few hundred nanometer size and Ag particles are aggregated. On the other hand, in Fig. 6d to 6f, which show the SEM images of the M20A-glass(35\%), Ag particles of the size of about $20 \mathrm{~nm}$ were 
shown on the fractured surface of glass but the aggregation of Ag particles was also shown.

Fig. 7 shows temperature dependences of the electrical resistance of the AP-glasses and N-glass thick films deposited on the alumina substrate after baking at $800^{\circ} \mathrm{C}$ for $2 \mathrm{~h}$. The baked $\mathrm{N}$-glass showed high resistance over $10^{6} \Omega$ at $400^{\circ} \mathrm{C}$ to $700^{\circ} \mathrm{C}$ and was non-conductive. In general, alkali ion-containing glasses are conductive because of the migration of alkali ions at high temperature. However, the N-glass contained two alkali oxides of $\mathrm{Na}_{2} \mathrm{O}$ and $\mathrm{K}_{2} \mathrm{O}$ and showed mixed-alkali effect, which causes to reduce the conductivity, resulting in the formation of non-conductive glass [10,11]. The baked AP-glass(30\%), AP-glass(33\%), AP-glass(43\%) and AP-glass(53\%) showed low resistances below $10 \Omega$ at $400^{\circ} \mathrm{C}$ to $700^{\circ} \mathrm{C}$. On the other hand, the baked AP-glass(20\%) and AP-glass(25\%) showed the resistances between the N-glass and AP-glass(30-53\%).

Whereas the electrical resistances of the baked N-glass, AP-glass(20\%) and AP-glass $(25 \%)$ decreased with temperature, the electrical resistance of the baked AP-glass(30-53\%) slightly increased with temperature. The electrical resistance of a metal such as $\mathrm{Ag}, \mathrm{Au}$ or Pd increases with temperature because of the thermal scattering of lattice vibration [12]. The electrical conduction pathways between Ag particles in the baked AP-glass(30-53\%) were formed by the baking process, so that the baked AP-glass(30-53\%) showed metallic conductivity. On the other hand, no electrical conduction pathways between $\mathrm{Ag}$ particles in the baked AP-glass(20\%) and AP-glass $(25 \%)$ were formed because of low Ag content, that is, the distance between the Ag particles are too long to enhance the conduction.

Fig. 8 shows the temperature dependences of the electrical resistance of the 
M300A-glasses and N-glass thick films deposited on the alumina substrate after baking at $800^{\circ} \mathrm{C}$ for $2 \mathrm{~h}$. The electrical resistances of the baked M300A-glass(40\%) and M300A-glass(50\%) were below $10 \Omega$ and increased with temperature from $400^{\circ} \mathrm{C}$ to $700^{\circ} \mathrm{C}$. The electrical conduction pathways between $\mathrm{Ag}$ particles in the M300A-glass(40\%) and M300A-glass(50\%) were formed by the baking process. On the other hand, The baked M300A-glass(35\%) showed electrical resistance over $10^{4} \Omega$ from $400^{\circ} \mathrm{C}$ to $700^{\circ} \mathrm{C}$; no electrical conduction pathways between $\mathrm{Ag}$ particles in the baked M300A-glass(35\%) were formed.

Fig. 9 shows the temperature dependences of the electrical resistance of the M20A-glasses and N-glass thick films deposited on the alumina substrate after baking at $800^{\circ} \mathrm{C}$ for $2 \mathrm{~h}$. The electrical resistances of the baked M20A-glass $(35 \%)$ and M20A-glass(40\%) were below $10 \Omega$ and slightly increased with temperature from $400^{\circ} \mathrm{C}$ to $700^{\circ} \mathrm{C}$. Fig. 10 shows Relationship between Ag content in the baked AP-glass, M300A-glass, M20A-glass or N-glass and electrical resistance at $700^{\circ} \mathrm{C}$. The baked M20A-glass(35\%) showed lower electrical resistance than the baked M300A-glass(35\%). To obtain the conductive glass sealant, the lower limit values of Ag content of the AP-glass, M300A-glass and M20A-glass were 30, 40 and 35wt\%, respectively. The baked AP-glass(30\%), M300A-glass(40\%) and M20A-glass(35\%) showed the electrical resistance of $4.3,4.1$ and $7.3 \Omega$, respectively, at $700^{\circ} \mathrm{C}$. They are almost comparable to the electrical resistance $(\sim 4 \Omega)$ of $\mathrm{Ag}$ paste in our preliminary experiment and that of insulator-conductor composites with silver particles [13]. The standard deviations of the AP-glass(30\%), M300A-glass(40\%) and M20A-glass(35\%) were estimated to be $0.005,0.008$ and $0.005 \Omega$, respectively, at $700^{\circ} \mathrm{C}$. Since the values of the standard deviations were much smaller than those of the electrical resistance, the 
length of the error bars was small. Therefore, the electrical resistance was sufficiently stable during the measurement.

In several reports of insulator-conductor composites, the electrical conductivities of the composites are influenced by the conductive filler properties such as size, content, dispersion state, aspect ratio, and distance between the fillers. To increase the electrical conductivity of the composite, the decrease of the filler size and the distance between the fillers is required [13-18]. Fig. 11 shows cross-sectional SEM images of the baked film of the AP-glass(33\%), M300A-glass(35\%) and M20A-glass(35\%) after the electrical resistance measurement. Since all the baked films showed dense and non-porous, the films would have good gas sealability. In Fig. 11a and Fig. 11b, the baked film of the AP-glass(33\%) showed the good uniformly dispersion of small Ag particles. On the other hand, in Fig. 11c to Fig. 11f, the baked films of the M300A-glass(35\%) and M20A-glass(35\%) showed the poor dispersion of Ag particles and had some large Ag aggregations. The electrical conductivity in the composites consisting of an intricate network of conductive and insulative phases is determined by two mechanisms, percolation in a continuous conductive network and/or tunneling between isolated conductive particles [19,20]. In Fig. 11, no continuous network consisting of Ag was observed, and the origin of the electrical conduction in the baked AP-glass, M300A-glass or M20A-glass was considered to be due to tunneling effect. Since the baked AP-glass had small Ag particle sizes and good uniformly dispersion of small Ag particles, the baked AP-glass showed better electrical conduction even at 30wt\% Ag content, compared to the M300A-glass and M20A-glass.

In this study, we have investigated the electrical properties of the AP-glass prepared by a new production method of heat reduction process and the M300A-glass 
and M20A-glass prepared by a conventional mixing method. The baked film of AP-glass showed lower electrical resistance even at 30wt\% Ag content. Further works are necessary to optimize the heat reduction condition of the AP-glass.

\section{Conclusions}

Novel conductive Ag-precipitated glass powder was successfully prepared by the heat reduction process of the glass/ $\mathrm{AgCl}$ composite powder and their microstructures and electrical properties were studied. The baked film of the Ag-precipitated glass powder with 30 to $53 \mathrm{wt} \% \mathrm{Ag}$ content showed good metallic electrical conduction from $400^{\circ} \mathrm{C}$ to $700^{\circ} \mathrm{C}$ in air. The electrical conduction of the Ag-precipitated glass powder resulted from uniformly dispersion of Ag particles. No continuous network of $\mathrm{Ag}$ particles was found in the microstructure observation of the glass powders, or films, the origin of the electrical conduction was considered to be due to tunneling effect between the well-dispersed Ag particles.

\section{Acknowledgement}

This research was partially supported by JST, CREST.

\section{References}

[1] Q.M. Zhang, H. Li, M. Poh, F. Xia, Z.Y. Cheng, H. Xu, C. Huang, An all-organic composite actuator material with a high dielectric constant, Nature 419 (2002) 284-287. [2] J.C. Jagt, P.J.M. Beris, G.F.C.M. Lijten, Electrically conductive adhesives: A prospective alternative for SMD soldering?, IEEE Trans. Comp., Packag., Manufact. Technol. B 18 (1995) 292-298. 
[3] Z. Sun, D. Pan, J. Wei, C.K. Wong, Ceramics bonding using solder glass frit, J. Electron. Mater. 33 (2004) 1516-1523.

[4] N.H. Menzler, D. Sebold, M. Zahid, S.M. Gross, T. Koppitz, Interaction of metallic SOFC interconnect materials with glass-ceramic sealant in various atmospheres, J. Power Sources 152 (2005) 156-167.

[5] T. Yamaguchi, S. Shimizu, T. Suzuki, Y. Fujishiro, M. Awano, Fabrication and evaluation of a novel cathode-supported honeycomb SOFC stack, Mater. Lett. 63 (2009) $2577-2580$.

[6] S.M. Gross, D. Federmann, J. Remmel, M. Pap, Reinforced composite sealants for solid oxide fuel cell applications, J. Power Sources 196 (2011) 7338-7342.

[7] H. Kaneko, T. Okamura, H. Taimatsu, Y. Matsuki, H. Nishida, Performance of a miniature zirconia oxygen sensor with a Pd-PdO internal reference, Sens. Actuators B 108 (2005) 331-334

[8] N. F. Borrelli, B. Wedding, Optical properties of chemically reduced photochromic glasses, J. Appl. Phys. 63 (1988) 2756-2759.

[9] R. Faddoul, N. Reverdy-Bruas, A. Blayo, Formulation and screen printing of water based conductive flake silver pastes onto green ceramic tapes for electronic applications, Mater. Sci. Eng. B 177 (2012) 1053-1066.

[10] D. E. Day, Mixed alkali glasses - Their properties and uses, J. Non-Cryst. Solids 21 (1976) 343-372.

[11] Y. Daiko, T. Yamada, A. Mineshige, M. Kobune, T. Yazawa, Preparation and fuel cell property of a phosphosilicate glass with proton transport number $t_{H}=1$ at 400-500 ${ }^{\circ}$ C, Electrochem. Solid-State Lett. 14 (2011) B63-B65.

[12] T. Kasuya, Electrical resistance of ferromagnetic metals, Prog. Theor. Phys. 16 
(1956) 58-63.

[13] H.P. Wu, J.F. Liu, X.J. Wu, M.Y. Ge, Y.W. Wang, G.Q. Zhang, J.Z. Jiang, High conductivity of isotropic conductive adhesives filled with silver nanowires, Int. J. Adhes. Adhes. 26 (2006) 617-621.

[14] D. Toker, D. Azulay, N. Shimoni, I. Balberg, O. Millo, Tunneling and percolation in metal-insulator composite materials, Phys. Rev. B 68 (2003) 041403.

[15] K.S. Deepa, M.S. Gopika, J. James, Influence of matrix conductivity and Coulomb blockade effect on the percolation threshold of insulator-conductor composites, Compos Sci Tech. 78 (2013) 18-23.

[16] J.K.W. Sandler, J.E. Kirk, I.A. Kinloch, M.S.P. Shaffer, A.H. Windle, Ultra-low electrical percolation threshold in carbon-nanotube-epoxy composites, Polymer 44 (2003) 5893-5899.

[17] J. Li, P.C. Ma, W.S. Chow, C.K. To, B.Z. Tang, J.-K. Kim, Correlations between percolation threshold, dispersion state, and aspect ratio of carbon nanotubes, Adv. Funct. Mater. 17 (2007) 3207-3215.

[18] K.S. Deepa, N.S. Kumari, P. Parameswaran, M.T. Sebastian, J. James, Effect of conductivity of filler on the percolation threshold of composites, Appl. Phys. Lett. 94 (2009) 142902.

[19] B. Abeles, H.L. Pinch, J.I. Gittleman, Percolation conductivity in $\mathrm{W}-\mathrm{Al}_{2} \mathrm{O}_{3}$ granular metal films, Phys. Rev. Lett. 35 (1975) 247-250.

[20] P. Sheng, B. Abeles, Y. Arie, Hopping Conductivity in Granular Metals, Phys. Rev. Lett. 31 (1973) 44. 


\section{Figure captions}

Fig. 1. Schematic drawing of the preparation of the N-glass, AP-glass, M300A-glass and M20A-glass.

Fig. 2. DTA curve of the N-glass.

Fig. 3. Photographs of the glass/ $\mathrm{AgCl}$ composite powder with the weight ratio of 60:40

(a) before and (b) after the heat reduction at $400^{\circ} \mathrm{C}$ for $40 \mathrm{~h}$ under $5 \% \mathrm{H}_{2} / 95 \% \mathrm{~N}_{2}$ atmosphere.

Fig. 4. XRD patterns of the glass/AgCl composite powder with the weight ratio of 60:40 (a) before and (b) after the heat reduction at $400{ }^{\circ} \mathrm{C}$ for $40 \mathrm{~h}$ under $5 \% \mathrm{H}_{2} / 95 \% \mathrm{~N}_{2}$ atmosphere.

Fig. 5. (a) SEM image of the AP-glass(33\%) particle. (b) SEM image of the AP-glass(33\%) particle surface. (c) BSE image of the AP-glass(33\%) particle surface. (d) enlarged SEM image of the AP-glass(33\%) particle surface.

Fig. 6. (a) SEM image of the M300A-glass(35\%) particle. (b) SEM image of the M300A-glass(35\%) particle surface. (c) SEM image of the high magnification of the spherical particle in the upper right corner of (a). (d) SEM image of the M20A-glass(35\%) particle. (e) SEM image of the M20A-glass(35\%) particle surface. (f) SEM image of the high magnification of the spherical particle in the upper right corner of (d). 
Fig. 7. Temperature dependences of the electrical resistance of the AP-glasses and $\mathrm{N}$-glass thick films deposited on the alumina substrate after baking at $800^{\circ} \mathrm{C}$ for $2 \mathrm{~h}$.

Fig. 8. Temperature dependences of the electrical resistance of the M300A-glasses and $\mathrm{N}$-glass thick films deposited on the alumina substrate after baking at $800^{\circ} \mathrm{C}$ for $2 \mathrm{~h}$.

Fig. 9. Temperature dependences of the electrical resistance of the M20A-glasses and $\mathrm{N}$-glass thick films deposited on the alumina substrate after baking at $800^{\circ} \mathrm{C}$ for $2 \mathrm{~h}$.

Fig. 10. Relationship between Ag content in the baked AP-glass, M300A-glass, M20A-glass or N-glass and electrical resistance at $700^{\circ} \mathrm{C}$. The error bars indicate standard deviations.

Fig. 11. Cross-sectional SEM images of the baked film of ( $a$ and $b$ ) the AP-glass(33\%), (c and d) M300A-glass(35\%) and (e and f) M20A-glass(35\%) after the electrical resistance measurement. 
Table 1. Ag contents of the AP-glass, M300A-glass and M20A-glass.

\begin{tabular}{|c|c|c|c|}
\hline & AP-glass & M300A-glass & M20A-glass \\
\hline \multirow{3}{*}{$\begin{array}{c}\text { Ag content } \\
\text { (wt\% / vol\%) }\end{array}$} & $20.0 / 6.7$ & $35.0 / 13.4$ & $20.0 / 6.7$ \\
\cline { 2 - 4 } & $25.0 / 8.7$ & $40.0 / 16.0$ & $25.0 / 8.7$ \\
\cline { 2 - 4 } & $30.0 / 10.9$ & $50.0 / 22.3$ & $30.0 / 10.9$ \\
\cline { 2 - 4 } & $43.0 / 17.7$ & & $35.0 / 13.4$ \\
\cline { 2 - 4 } & $53.0 / 24.4$ & & $40.0 / 16.0$ \\
\cline { 2 - 4 } & & & \\
\hline
\end{tabular}




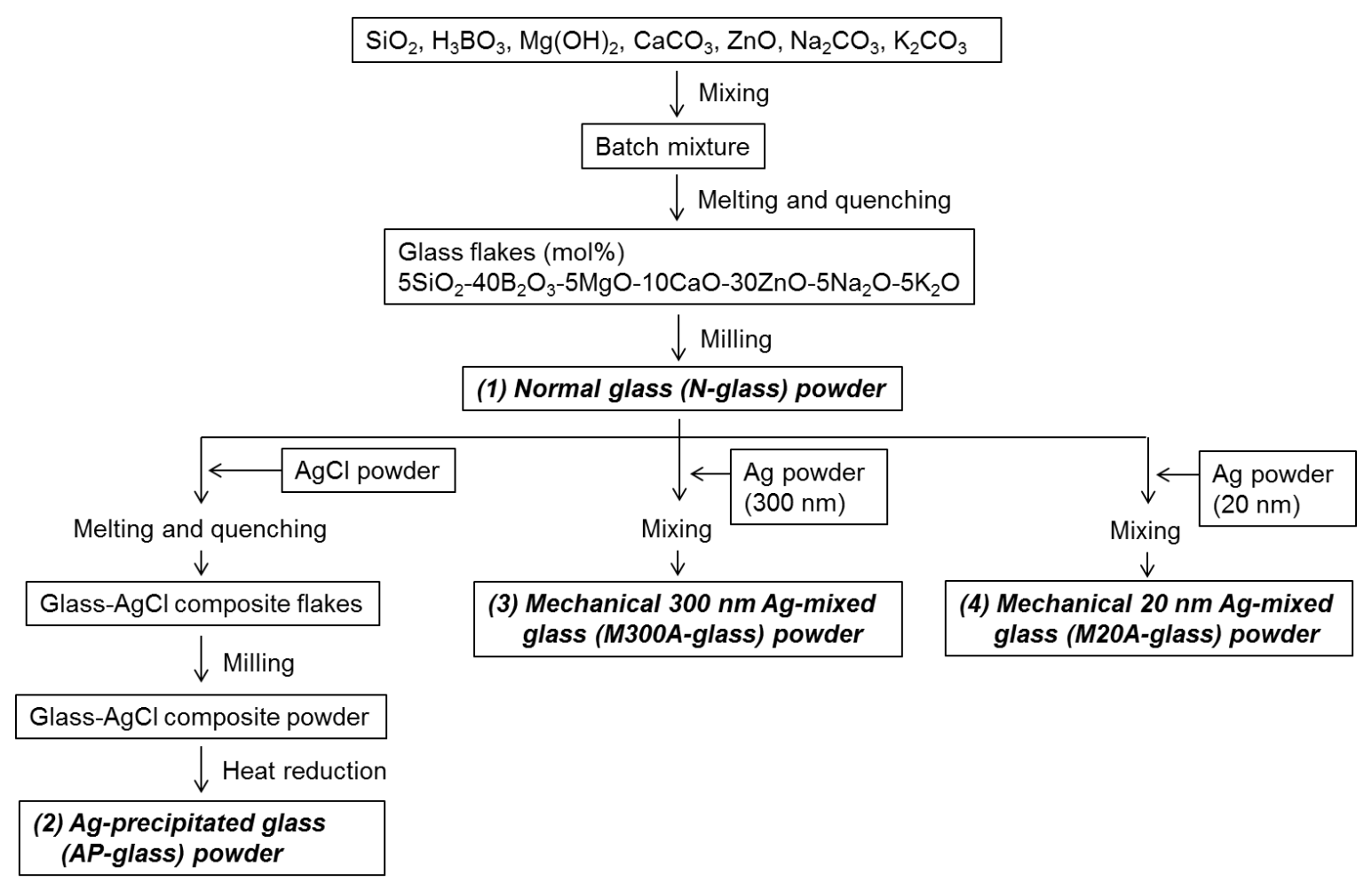

Fig. 1. Schematic drawing of the preparation of the N-glass, AP-glass, M300A-glass and M20A-glass. 


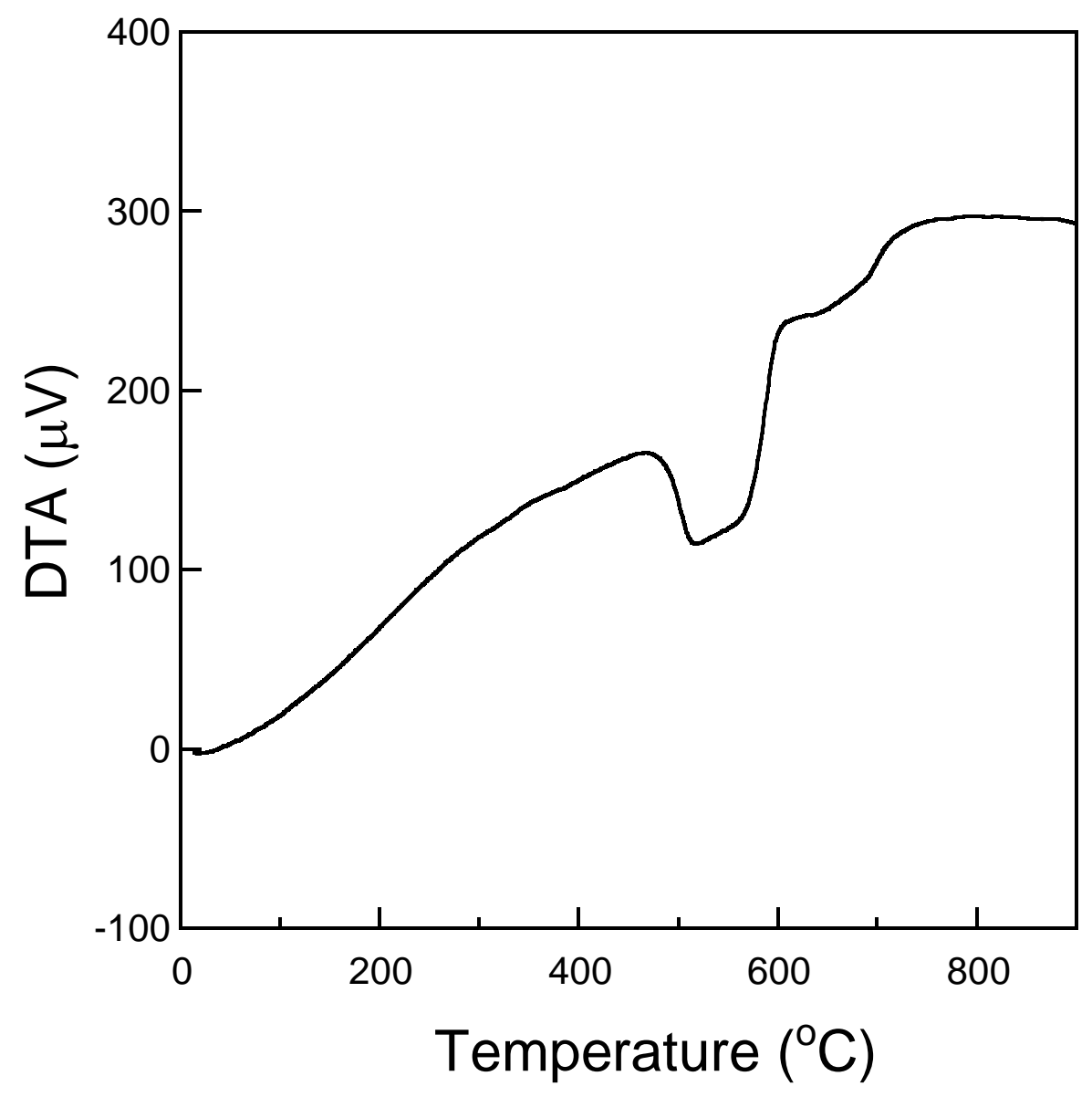

Fig. 2. DTA curve of the N-glass. 


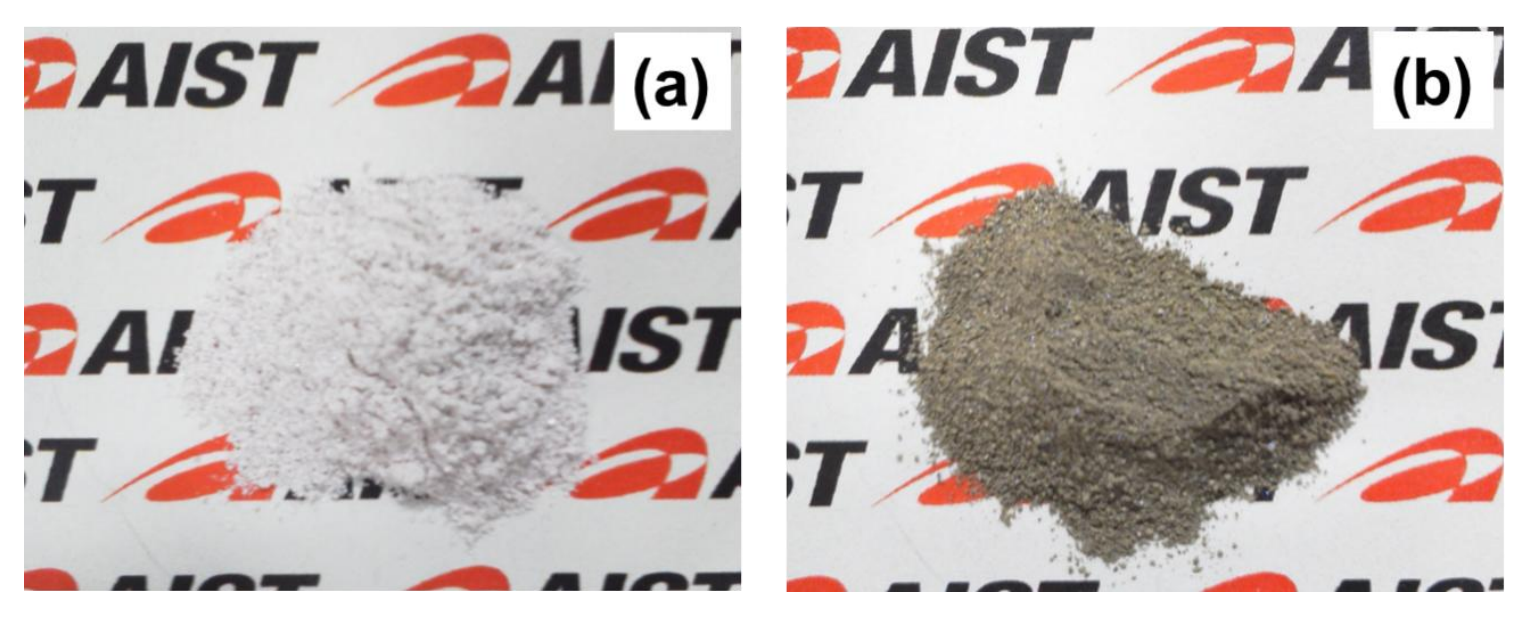

Fig. 3. Photographs of the glass/ $\mathrm{AgCl}$ composite powder with the weight ratio of 60:40 (a) before and (b) after the heat reduction at $400^{\circ} \mathrm{C}$ for $40 \mathrm{~h}$ under $5 \% \mathrm{H}_{2} / 95 \% \mathrm{~N}_{2}$ atmosphere. 


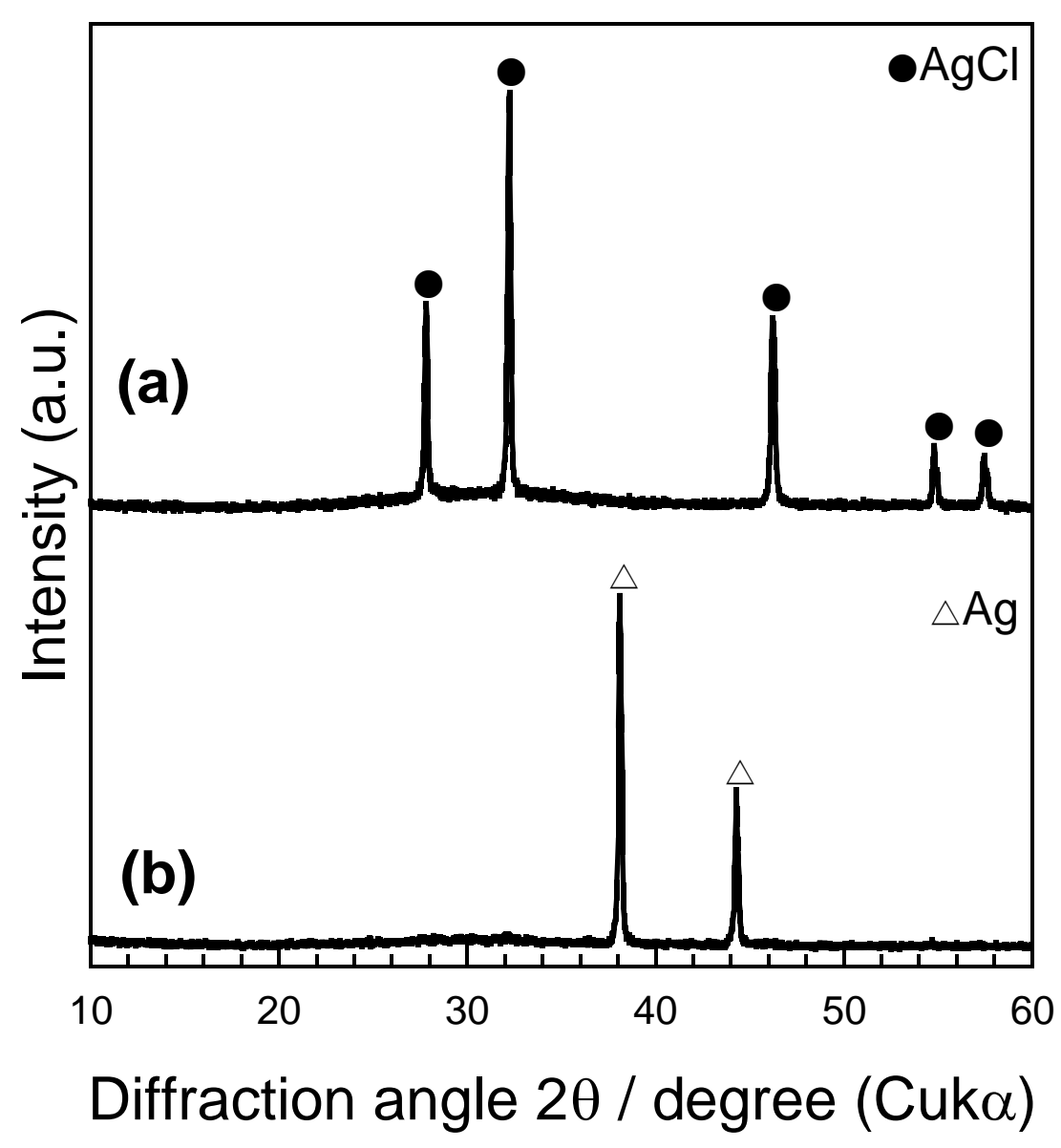

Fig. 4. $\mathrm{XRD}$ patterns of the glass/ $\mathrm{AgCl}$ composite powder with the weight ratio of 60:40 (a) before and (b) after the heat reduction at $400^{\circ} \mathrm{C}$ for $40 \mathrm{~h}$ under $5 \% \mathrm{H}_{2} / 95 \% \mathrm{~N}_{2}$ atmosphere. 

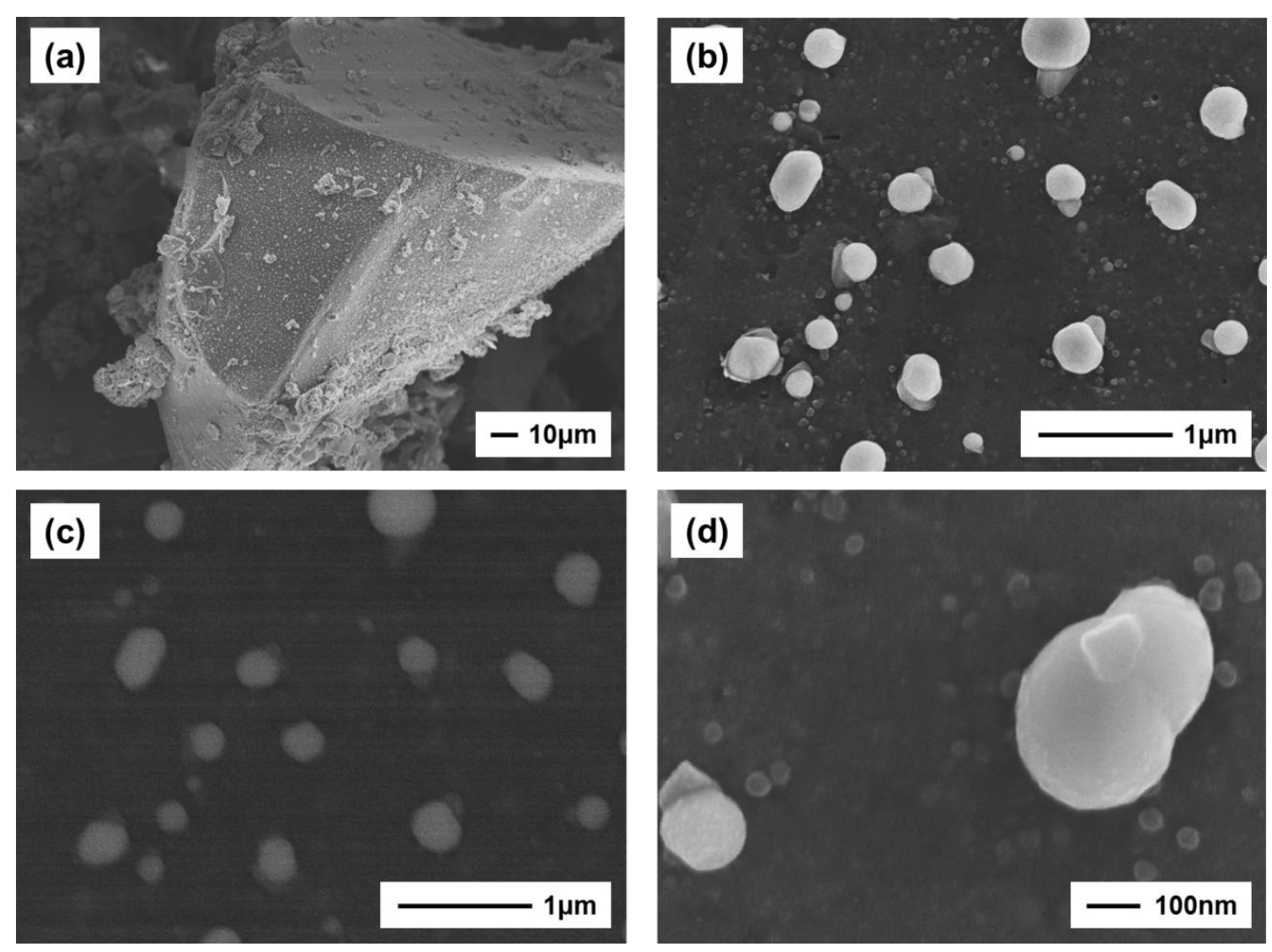

Fig. 5. (a) SEM image of the AP-glass(33\%) particle. (b) SEM image of the AP-glass(33\%) particle surface. (c) BSE image of the AP-glass(33\%) particle surface. (d) enlarged SEM image of the AP-glass(33\%) particle surface. 

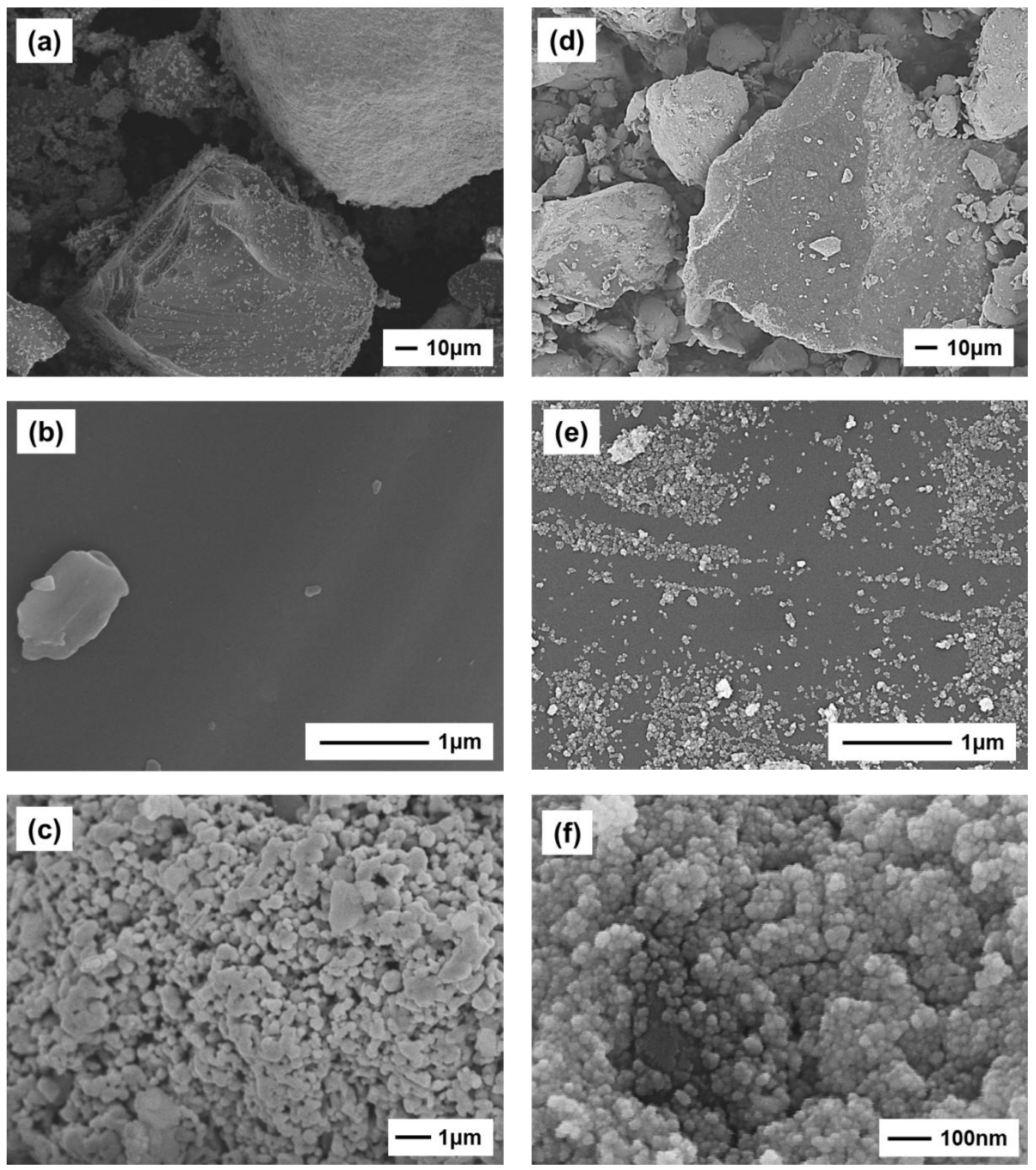

Fig. 6. (a) SEM image of the M300A-glass(35\%) particle. (b) SEM image of the M300A-glass(35\%) particle surface. (c) SEM image of the high magnification of the spherical particle in the upper right corner of (a). (d) SEM image of the M20A-glass(35\%) particle. (e) SEM image of the M20A-glass(35\%) particle surface. (f) SEM image of the high magnification of the spherical particle in the upper right corner of (d). 


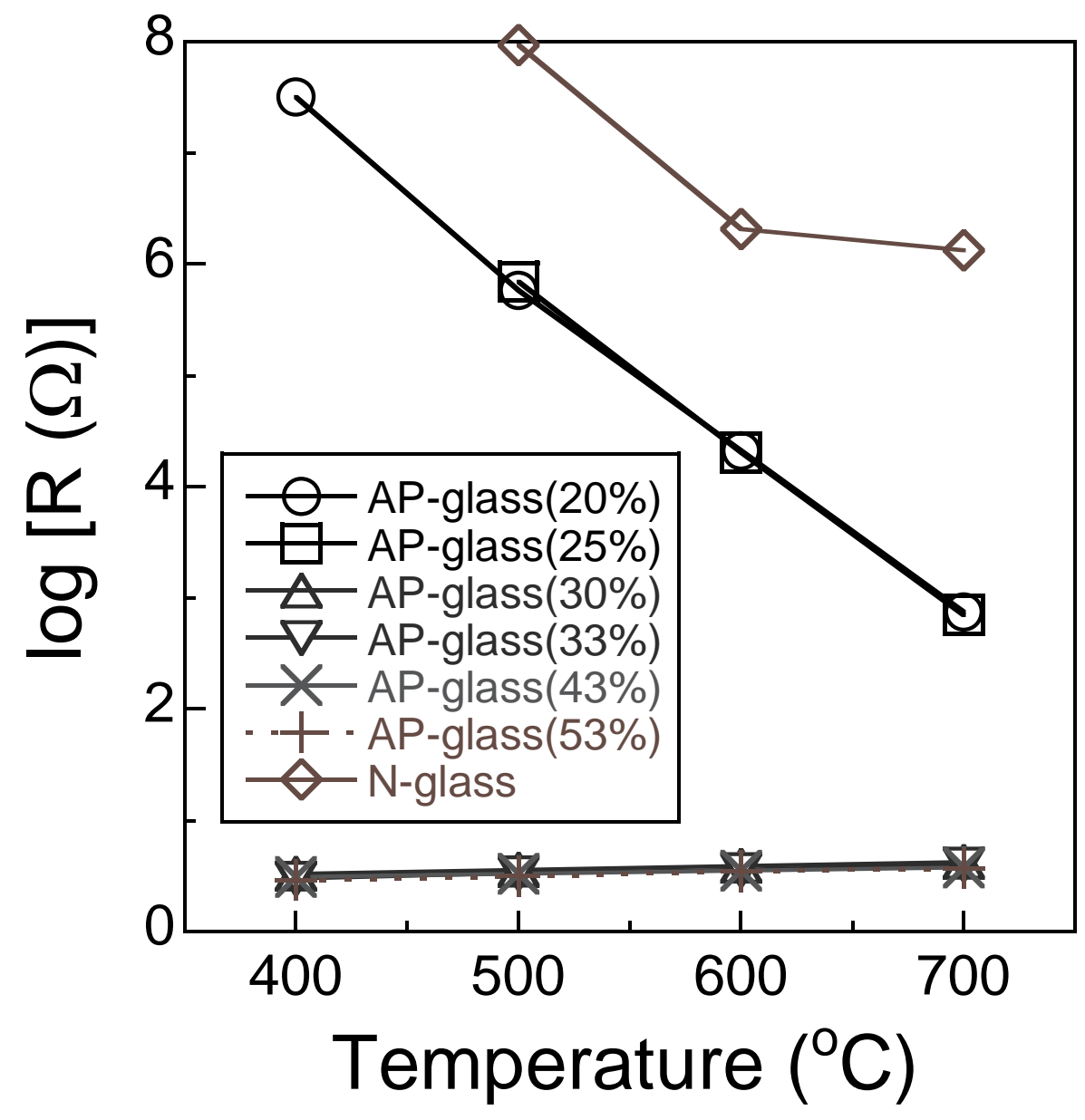

Fig. 7. Temperature dependences of the electrical resistance of the AP-glasses and $\mathrm{N}$-glass thick films deposited on the alumina substrate after baking at $800^{\circ} \mathrm{C}$ for $2 \mathrm{~h}$. 


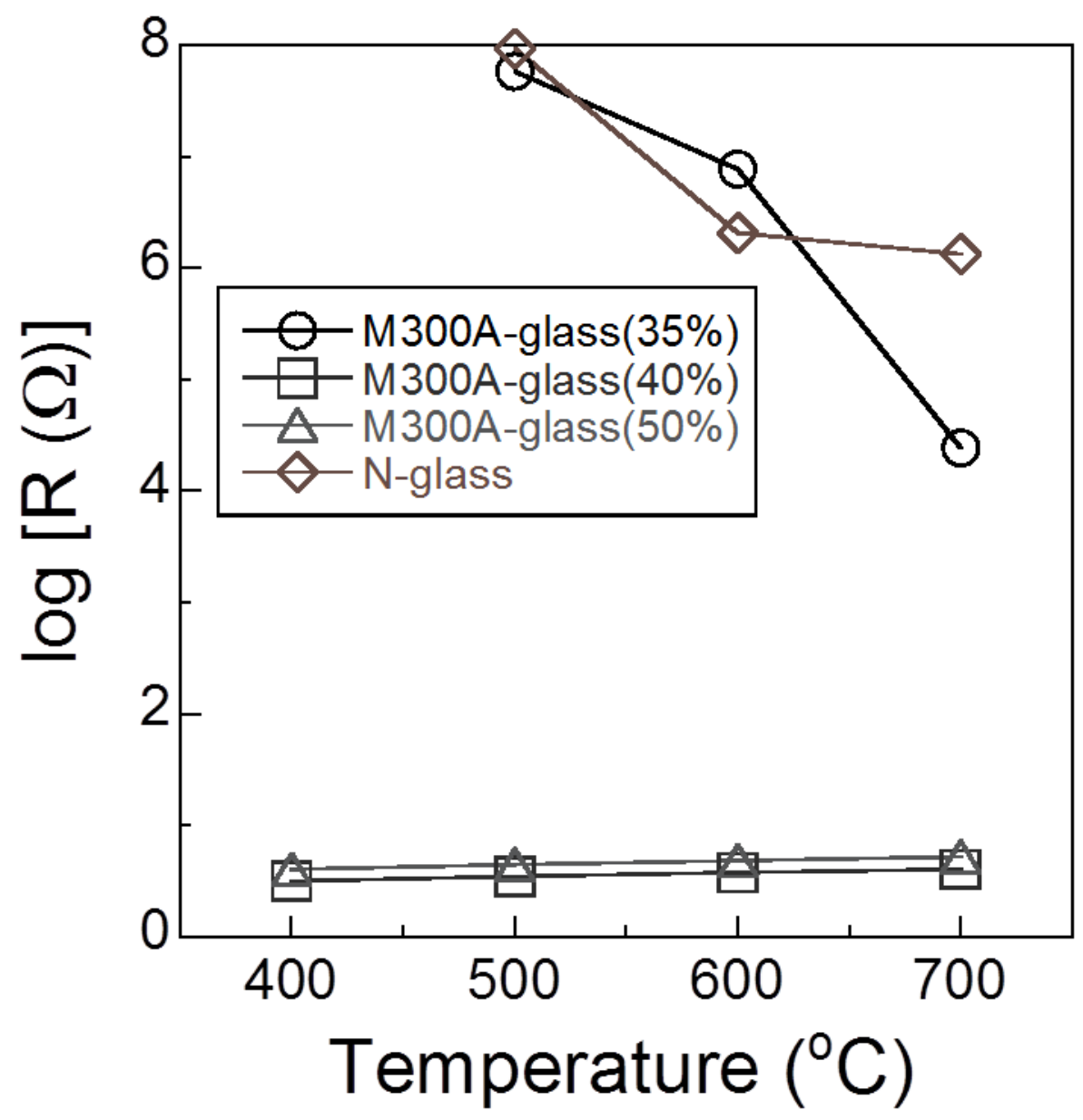

Fig. 8. Temperature dependences of the electrical resistance of the M300A-glasses and $\mathrm{N}$-glass thick films deposited on the alumina substrate after baking at $800^{\circ} \mathrm{C}$ for $2 \mathrm{~h}$. 


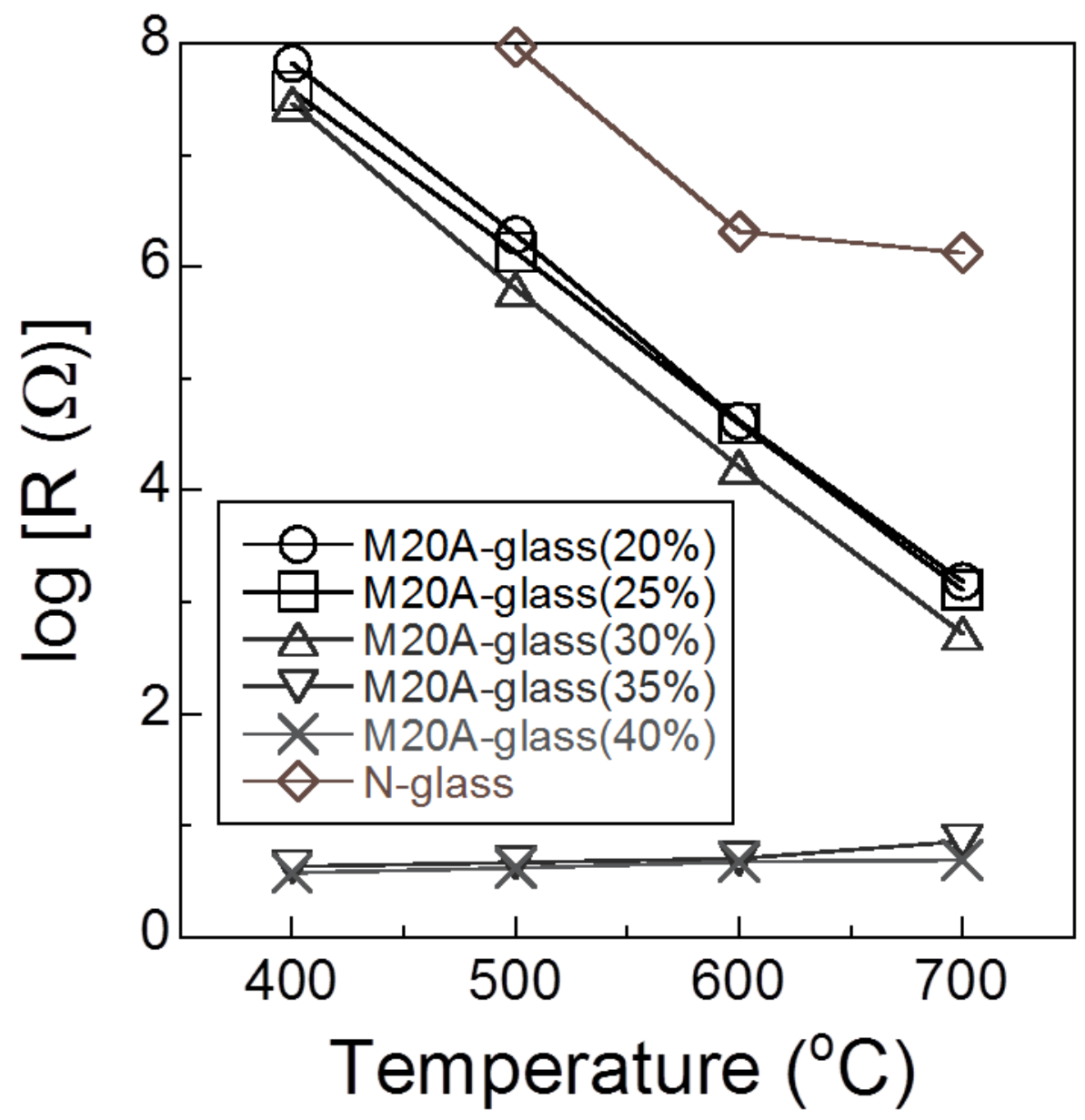

Fig. 9. Temperature dependences of the electrical resistance of the M20A-glasses and $\mathrm{N}$-glass thick films deposited on the alumina substrate after baking at $800^{\circ} \mathrm{C}$ for $2 \mathrm{~h}$. 


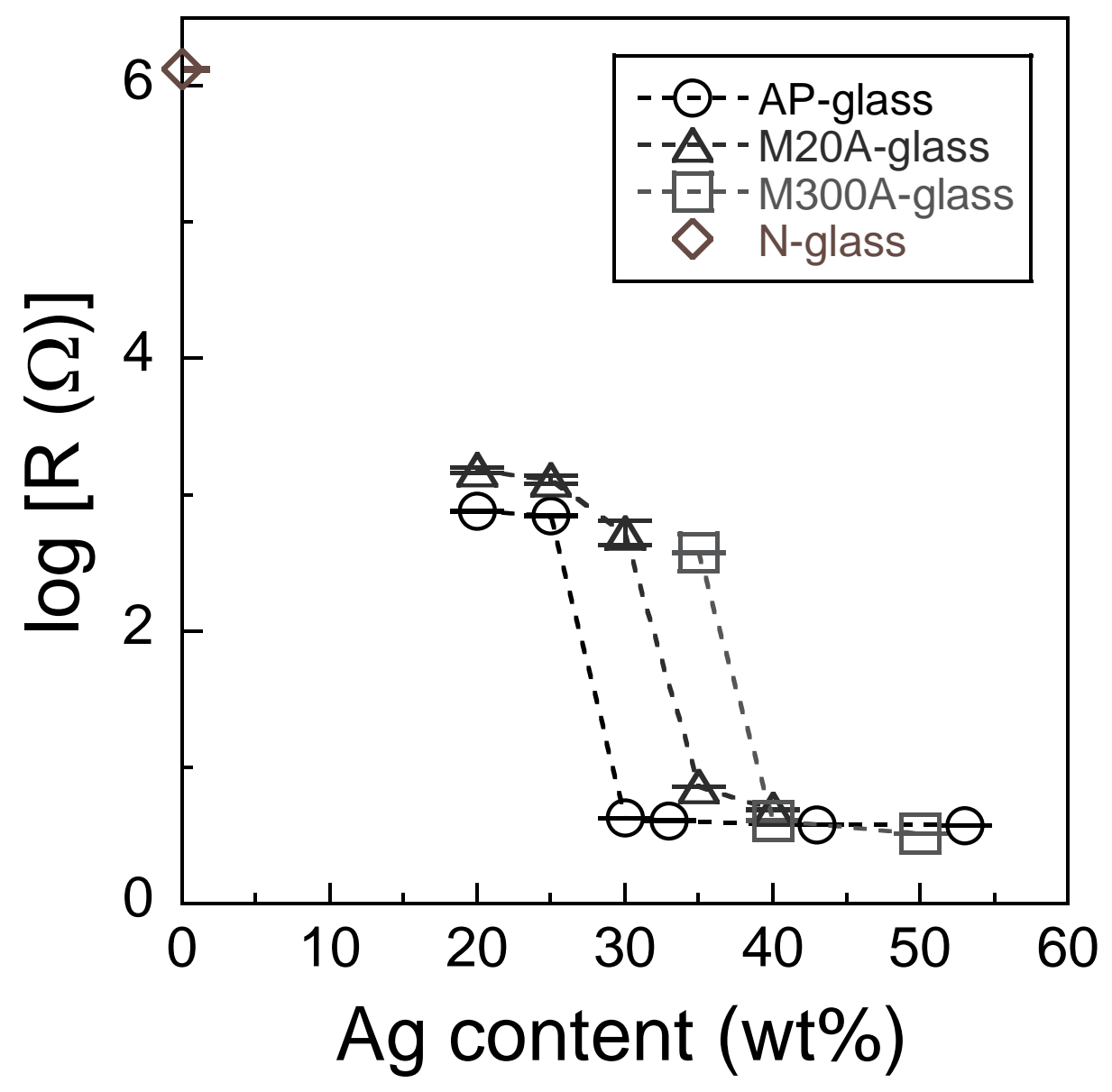

Fig. 10. Relationship between Ag content in the baked AP-glass, M300A-glass, M20A-glass or N-glass and electrical resistance at $700^{\circ} \mathrm{C}$. The error bars indicate standard deviations. 

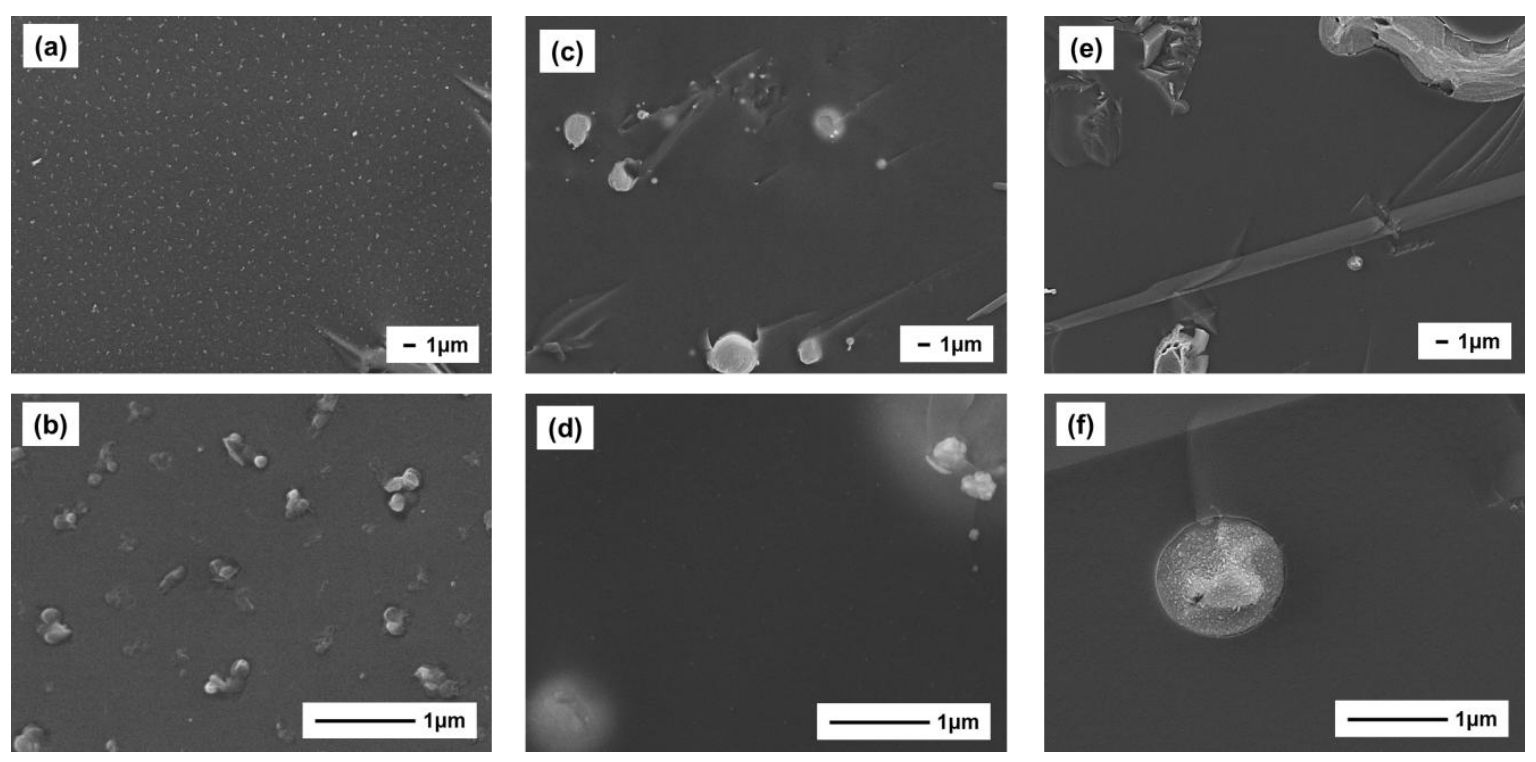

Fig. 11. Cross-sectional SEM images of the baked film of ( $a$ and $b$ ) the AP-glass(33\%), (c and d) M300A-glass(35\%) and (e and f) M20A-glass(35\%) after the electrical resistance measurement. 